University of Nebraska - Lincoln

DigitalCommons@University of Nebraska - Lincoln

Faculty Publications from the Center for Plant

Science Innovation

Plant Science Innovation, Center for

2005

\title{
Folate Synthesis and Metabolism in Plants and Prospects For Biofortification
}

\author{
Gilles J. C. Basset \\ University of Nebraska-Lincoln, gbasset@ufl.edu \\ Eoin P. Quinlivan \\ University of Florida \\ Jesse F. Gregory III \\ University of Florida \\ Andrew D. Hanson \\ University of Florida, adha@mail.ifas.ufl.edu
}

Follow this and additional works at: https://digitalcommons.unl.edu/plantscifacpub

Part of the Plant Sciences Commons

Basset, Gilles J. C.; Quinlivan, Eoin P.; Gregory, Jesse F. III; and Hanson, Andrew D., "Folate Synthesis and Metabolism in Plants and Prospects For Biofortification" (2005). Faculty Publications from the Center for Plant Science Innovation. 72.

https://digitalcommons.unl.edu/plantscifacpub/72

This Article is brought to you for free and open access by the Plant Science Innovation, Center for at DigitalCommons@University of Nebraska - Lincoln. It has been accepted for inclusion in Faculty Publications from the Center for Plant Science Innovation by an authorized administrator of DigitalCommons@University of Nebraska Lincoln. 


\title{
Folate Synthesis and Metabolism in Plants and Prospects For Biofortification
}

\author{
Gilles J. C. Basset ${ }^{1}$, Eoin P. Quinlivan ${ }^{1}$, Jesse F. Gregory III, and Andrew D. Hanson*
}

\begin{abstract}
Folates are essential cofactors for one-carbon transfer reactions in most living organisms and are required for the biosynthesis of nucleic acids, amino acids, and pantothenate. Unlike plants and microorganisms, humans cannot synthesize folates de novo and must acquire them from the diet, primarily from plant foods. However, lack of folates is the most common vitamin deficiency in the world and has serious health consequences, including increased risk of neural tube defects in infants, cancers, and vascular diseases. Consequently, there is much interest in engineering plants with enhanced folate content (biofortification). In this review, we outline progress in defining the plant folate synthesis pathway and its unique compartmentation and point out sectors of folate metabolism that have yet to be elucidated, including transport and catabolism. We also consider possible strategies to enhance plant folate synthesis and accumulation by metabolic engineering.
\end{abstract}

$T$ ETRAHYDROFOLATE (THF) and its derivatives - commonly grouped under the name of folates - are vital cofactors for enzymes that mediate one-carbon transfer reactions. Folates are tripartite molecules, composed of pterin, $p$-aminobenzoate ( $p \mathrm{ABA})$, and glutamate moieties (Fig. 1). One-carbon units at various oxidation levels are attached at $\mathrm{N}-5$ of the pterin moiety, N-10 of the pABA moiety, or bridged between the two. As major carriers and donors of one-carbon units, folates are involved in a wide range of key metabolic functions including the biosynthesis of nucleic acids, amino acids and pantothenate, and-specifically in plants - in lignin formation and photorespiration (Hanson and Roje, 2001).

Natural folates occur predominantly as polyglutamylated molecules with a short $\gamma$-linked chain of glutamyl residues attached to the first glutamate. These polyglutamylated folates are the preferred substrates for most folate-dependent enzymes (Cossins, 2000; Scott et al., 2000). On the other hand, folate transporters - at least, those known in animals - generally prefer monoglutamate forms (Scott et al., 2000). Natural folates are all, to varying degrees, unstable, particularly to oxidative cleavage between the pterin and $p$ ABA moieties (Fig. 1; Scott et al., 2000) and this process is promoted by light. However, in vivo, folates may be stabilized by antioxidant compounds (ascorbate, glutathione) and by bind-

${ }^{1}$ These authors contributed equally to this article.

G.J.C. Basset and A.D. Hanson, Horticultural Sciences Dep., E.P. Quinlivan and J.F. Gregory III, Food Science and Human Nutrition Dep., University of Florida, Gainesville, FL 32611. This work was supported in part by the Florida Agricultural Experiment Station, by an endowment from the C.V. Griffin, Sr. Foundation and by grant MCB-0129944 from the National Science Foundation. Journal Series no. R-09861. Received November 2, 2003. Symposia. *Corresponding author(adha@mail.ifas.ufl.edu).

Published in Crop Sci. 45:449-453 (2005).

(c) Crop Science Society of America

677 S. Segoe Rd., Madison, WI 53711 USA ing to proteins (Scott et al., 2000). Folates are present in plants in trace quantities. Typically, plant folate contents range from 2 to 5 (leaves), 0.2 to 2 (roots), and 0.05 to 0.5 (fruits) $\mathrm{nmol} \mathrm{g}^{-1}$ fresh weight (Cossins, 2000; Gambonnet et al., 2001). With the exception of seeds, where 5-formyl-THF predominates, 5-methyl-THF is usually the major folate in plants (Shin et al., 1975; Cossins, 2000).

Unlike plants and microorganisms, animals cannot synthesize folates de novo and depend entirely on their dietary supply. For humans, plant foods are the single most important source of folates (Scott et al., 2000). Compelling epidemiological evidence shows that folate intake is suboptimal for most of the world's population, including - surprisingly - many industrialized nations, where food abundance and variety are supposed to be good (Lucock, 2000; Scott et al., 2000). Low folate intake is thought to contribute to the etiology of several major diseases such as cancer, cardiovascular disease, and neural tube defects (Scott et al., 2000). Fortification programs in the USA with synthetic folic acid have very effectively decreased the incidence of folate deficiency but may have health drawbacks in cases of excessive intake (Lucock, 2000; Quinlivan and Gregory, 2003). Moreover, food fortification is difficult to implement in poor countries, as is supplementation of the diet with folic acid pills. Engineering plants with enhanced folate content (biofortification) is therefore a rational alternative in addressing global folate malnutrition. It is also a cost-effective approach, since fortification or supplementation incurs the same recurrent costs year after year in country after country (Bouis, 2002).

\section{Folate Biosynthesis and Compartmentation}

The plant folate synthesis pathway is essentially the same as in bacteria, and it is now almost completely elucidated. Of 10 enzymes specific to the pathway, eight have been cloned and characterized from plants (Fig. 2). In addition, a reaction unique to plants - the reversible esterification of $p$ ABA with glucose-has been identified (Quinlivan et al., 2003).

\section{Pterin Branch}

The first step of the plant pterin branch is catalyzed by an unusual GTP cyclohydrolase I (GTPCHI, Fig. 2) which is formed of two similar domains, each homologous to GTPCHIs from other organisms (Basset et al., 2002). Genomic evidence suggests that plant GTPCHIs lack targeting peptides and hence are cytosolic enzymes. Our attempts to confirm this by quantifying the distribution of GTPCHI activity among subcellular fractions

Abbreviations: $p \mathrm{ABA}, p$-aminobenzoate; ADC, aminodeoxychorismate; DHN, dihydroneopterin; FPGH, folylpoly- $\gamma$-glutamate hydrolase; GTPCHI, GTP cyclohydrolase I; THF, tetrahydrofolate. 


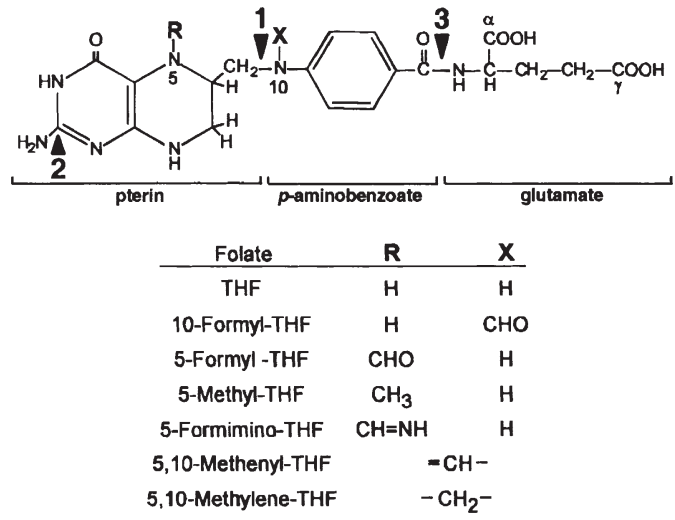

Fig. 1. Chemical structures of tetrahydrofolate and its $\mathrm{C1}$-substituted derivatives. Natural folates occur mainly as polyglutamylated forms in which a $\gamma$-linked chain of up to about eight residues is added to the glutamate moiety. Numbered arrowheads mark potential sites of action of catabolic enzymes (see text). The removal of the polyglutamyl tail after the first glutamate (reaction 4 , mentioned in the text) is not shown on this figure.

of tomato leaves have failed because of an interfering activity in the cytosolic and chloroplast fractions degrading the reaction product dihydroneopterin (DHN) triphosphate. However, as this degradative activity is absent from purified mitochondria, we have been able to demonstrate that this organelle has no detectable GTPCHI activity $\left(<0.01 \mathrm{pmol} \mathrm{min}^{-1} \mathrm{mg}^{-1}\right.$ protein). This confirms that GTPCHI is extramitochondrial. The dephosphorylation of DHN triphosphate (Fig. 2) occurs in two stages. The first is loss of pyrophosphate; in bacteria, this reaction is most probably mediated by a specific pyrophosphatase (Suzuki and Brown, 1974; Lee et al., 1999), although a chemical process has also been suggested (De Saizieu et al., 1995). The nature of the reaction in plants is unknown. The remaining phosphate is then cleaved off by a nonspecific phosphatase. In bacteria, the cleavage of the three-carbon side chain of DHN is mediated by DHN aldolase (Fig. 2). This enzyme has not yet been cloned from plants.

\section{pABA Branch}

As in bacteria, the first step in the conversion of chorismate to $p \mathrm{ABA}$ is mediated in plants by aminodeoxychorismate (ADC) synthase (Fig. 2). However, while the bacterial ADC synthase is a heterodimer, the plant enzyme is a bipartite fusion protein with tandem domains homologous to the two bacterial subunits (Basset et al., 2004). Subcellular localization experiments show that the plant ADC synthase is plastidial (Basset et al., 2004). In bacteria, ADC is subsequently aromatized to pABA by ADC lyase (Nichols et al., 1989; Green et al., 1992) (Fig. 2), and it appears likely that there is a similar, as yet unidentified, enzyme in plants (Basset et al., 2004). Interestingly, it has been shown that $p \mathrm{ABA}$ is reversibly converted to its glucose ester by a cytosolic glucosyltransferase and that all or most $p \mathrm{ABA}$ may be esterified in planta (Quinlivan et al., 2003). This esterification process is apparently specific to plants although the physiological role of the ester is not yet elucidated. It may serve as a storage form of $p \mathrm{ABA}$, and may be the

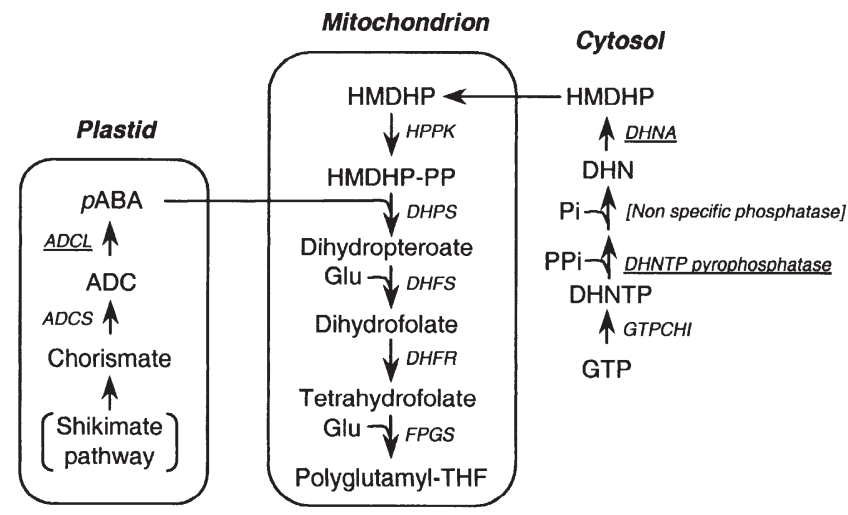

Fig. 2. The tetrahydrofolate biosynthesis pathway in plants. The enzymes that have not yet been cloned from plants are underlined. ADC, aminodeoxychorismate; DHN, dihydroneopterin; DHNTP, dihydroneopterin triphosphate; Glu, glutamate; GTP, guanosine 5' -triphosphate; HMDHP, hydroxymethyldihydropterin; HMDHPPPi, hydroxymethyldihydropterin pyrophosphate, $p \mathrm{ABA}, p$-aminobenzoate; PPi, pyrophosphate; Pi, inorganic phosphate; $\mathrm{ADCS}$, aminodeoxychorismate synthase; ADCL, aminodeoxychorismate lyase; GTPCHI, GTP cyclohydrolase I; DHFR, dihydrofolate reductase; DHFS, dihydrofolate synthase; DHNA, dihydroneopterin aldolase; DHPS, dihydropteroate synthase; FPGS, folylpolyglutamate synthetase; HPPK, hydroxymethyldihydropterin pyrophosphokinase. Note that there are cytosolic and plastidial isoforms of FPGS as well as the mitochondrial enzyme shown (Ravanel et al., 2001).

form in which $p \mathrm{ABA}$ is trafficked within plant cells (Quinlivan et al., 2003).

\section{Synthesis of Folates from Pterin, $p \mathrm{ABA}$, and Glutamate Moieties}

The last five steps of the plant folate synthesis pathway are localized in mitochondria (Neuburger et al., 1996; Rébeillé et al., 1997; Ravanel et al., 2001) (Fig. 2). The pterin and $p$ ABA moieties are coupled by dihydropteroate synthase, which in plants is part of a bifunctional protein that also contains the next enzyme in the pathway, hydroxymethyldihydropterin pyrophosphokinase. Plant dihydropteroate synthase is feedback inhibited by its own product, dihydropteroate (Prabhu et al., 1997). The first glutamylation step is catalyzed in plants by a dihydrofolate synthase and subsequent glutamylations by folylpolyglutamate synthase (Ravanel et al., 2001). The reduction of dihydrofolate to THF is mediated by a bifunctional dihydrofolate reductase that also has thymidylate synthase activity.

\section{Compartmentation and Transport}

It is noteworthy that the plant folate biosynthesis pathway is split among cytosol, mitochondria, and chloroplasts, whereas it is cytosolic in other organisms. Folates are present in most if not all plant cell compartments; for instance in pea leaves, folate is distributed in a 30/ 3/67 ratio among mitochondria, chloroplasts, and a fraction consisting of the cytosol, nucleus, and vacuole (Gambonnet et al., 2001). Thus, the latter fraction contains the bulk of plant folates, but mitochondria, which represent only a few percent of the cell volume, have the highest concentration, whereas plastids have the lowest (Gam- 


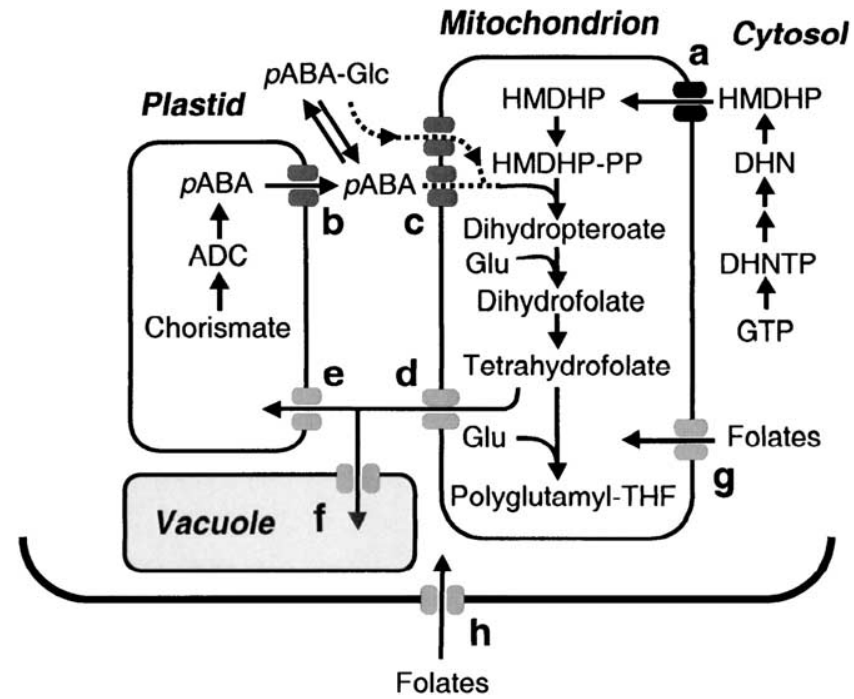

Fig. 3. Transport of folates and precursors in plants. Letters indicate inferred transport steps (see text). Abbreviations are as in the legend of Fig. 2.

bonnet et al., 2001). Folates and their biosynthetic intermediates must therefore move in and out of organelles, thus requiring transport mechanisms (Fig. 3). These transport steps include the following: (a) pterin import into mitochondria; (b) $p$ ABA export from plastids; (c) $p \mathrm{ABA}$ (or $p \mathrm{ABA}$ glucose ester) import into mitochondria; (d) folate export from mitochondria; (e) folate import into plastids; and (f) possibly folate import into vacuoles. In addition, there is evidence for import of 5-formyl-THF into mitochondria (g) as well as folate uptake from outside the cell (h) (Prabhu et al., 1998). There are presumably transporters corresponding to all eight steps, a-h, although there are not necessarily eight different types of transporters since one type may mediate several transport processes (e.g., a, d, and $\mathbf{g}$ ).

Folate and pterin transporters have been characterized and cloned from animals (Kundig et al., 1999; Sirotnak and Tolner, 1999; Titus and Moran, 2000), but no transporters have yet been identified in plants. As a hydrophobic weak acid, $p$ ABA may diffuse freely across membranes, but a transporter may be needed if $p \mathrm{ABA}$ is trafficked in the form of its hydrophilic glucose ester (Quinlivan et al., 2003).

\section{Folate Catabolism}

Very little is known about folate turnover in plants or about changes in folate content during development. Measurements of tomato fruit folate have shown a decrease during ripening (Basset et al., 2002), and substantial decreases have been reported for strawberries, spinach, and peas during postharvest storage (Scott et al., 2000; Strålsjö et al., 2003). However, it is unclear whether this postharvest decline is enzymatic or due to chemical breakdown as endogenous antioxidants are depleted (Scott et al., 2000). In principle, the reactive oxygen species produced by mitochondria and plastids can promote the chemical breakdown of folates, and leaf folates may also be exposed to oxidative cleavage promoted by light (Hanson and Gregory, 2002). In this connection, it is in- teresting to note that UVC irradiation can promote the accumulation of a photolysis product of folates (6-carboxypterin) in pea leaves (Stakhov et al., 2002).

There are no reports of enzyme-mediated folate catabolism in plants, but some inferences may be drawn from studies of other organisms (Scott, 1984). Thus, there are potentially four degradative pathways in plants (Fig. 1): (1) enzymatic scission between the pterin and the $p$ ABA-glutamyl moieties (as also occurs during oxidative cleavage); (2) deamination of the pteridine ring; (3) hydrolysis of the $p$ ABA-glutamyl linkage of folates or $p$ ABA-glutamate; and (4) removal of the polyglutamyl tail, leaving just the first glutamate. There is indirect evidence for the presence of two of these reactions in plants. Reaction 2 is implied by the presence of lumazines, which may originate from deaminated folates (Kobayashi et al., 1967). Reaction 4 is implied by the observation that plants have genes that encode homologs of both mammalian types of folylpoly- $\gamma$-glutamate hydrolase (FPGH). None of these homologs has yet been shown to have FPGH activity. However, the FPGH protein has been found to be extracellular in soybean (Huangpu et al., 1996), and mutants of an Arabidopsis FPGH gene are morphologically abnormal (Helliwell et al., 2001).

Other degradation mechanisms in plants are speculative, and clues for their existence come from comparative biochemistry and genomics. For instance, ferritin has been shown to promote Reaction 1 in animal cells (Suh et al., 2000). As plastids contain ferritin, this process could occur in plants. It has also been found that Reaction 1 is a secondary catalytic activity of mammalian 5-formyl-THF cycloligase (Anguera et al., 2003). This enzyme has been recently cloned in plants and has been located in mitochondria (Roje et al., 2002).

\section{Metabolic Engineering of Folate Levels in Plants}

Conceptually, there are three potential strategies for engineering higher folate: (i) increasing synthesis by overexpressing one or more enzymes (or transporters) that mediate steps that limit overall flux through the pathway; (ii) increasing the transport of folates into the vacuole or other metabolically inert compartment where they can be stockpiled; and (iii) decreasing chemical and enzymatic breakdown, either by downregulation of catabolic enzymes, or by rerouting folate synthesis toward 5-formyl-THF, which is the most stable natural folate. These strategies are not mutually exclusive, and it is likely that a combination will be synergistic.

\section{Overexpression of Folate Synthesis Enzymes}

Overexpressing the committing enzymes at the head of pathways is a standard gambit in metabolic engineering. Such an approach has been effective in the lactic acid bacterium Lactococcus lactis whereby overexpression of its own GTPCHI increased folate production by threefold (Sybesma et al., 2003). As bacterial GTPCHI is subject to feedback inhibition (Schoedon et al., 1992), using a GTPCHI released from feedback regulation is potentially more effective. We are currently exploring 
such a strategy with the construction of transgenic tomato lines expressing vertebrate GTPCHIs (animals have GTPCHI for the production of another cofactor, tetrahydrobiopterin). Vertebrate GTPCHIs are feedback-regulated by a special feedback regulatory protein (Yoneyama and Hatakeyama, 1998), and as plants do not have homologs of this protein, the animal enzymes are expected to be deregulated in plants. Similar to mammals and bacteria, in which DHN triphosphate is a precursor to a number of pterins (Brown, 1985), DHN triphosphate and DHN itself are potential branch points in the folate synthesis pathway. Consequently, it is possible that overexpressing DHN triphosphate pyrophosphatase and DHN aldolase could channel pterins toward folate production. The plant ADC synthase does not appear to be directly inhibited by either $p$ ABA or folates in vitro (Basset et al., 2004), but potential regulators may exist in plastids. Thus, one strategy for freeing plant ADC synthase from regulatory mechanisms could be to overexpress an ADC synthase that is retargeted to the cytosol.

As mentioned above, dihydropteroate is a product inhibitor of dihydropteroate synthase, regulating its own synthesis and preventing its accumulation in mitochondria (Scott et al., 2000). Because dihydropteroate competitively blocks binding of both the pterin and $p \mathrm{ABA}$ substrates, it is unlikely that the synthase can be engineered to decrease product inhibition without reducing activity. Product inhibition of this enzyme may therefore be better dealt with by overexpressing the next enzyme, dihydrofolate synthase, thereby minimizing dihydropteroate accumulation. Because dihydrofolate is highly labile (Quinlivan et al., 2000), it may also be necessary to overexpress dihydrofolate reductase if the endogenous activity is too low to accommodate the increased dihydrofolate production.

\section{Modified Folate Transport and Compartmentation}

Even if $p \mathrm{ABA}$ and pterin overproduction are achieved, folate production might still be limited by the transport of these precursors into mitochondria. Since nothing is known about plant $p \mathrm{ABA}$, pterin, or folate carriers, identifying and cloning these transporters is a priority for metabolic engineering of plant folate biosynthesis. Besides its potential to increase biosynthetic flux, the engineering of folate transport is also a potential strategy to stockpile folate within an inert compartment such as the vacuole. As the folate biosynthetic enzymes are not present in the vacuole, it may be possible to accumulate folate without feedback inhibition of its synthesis by directing folate import into this organelle.

\section{Stabilization of the Folate Pool}

Since 5-formyl-THF is the most stable natural folate, it is an attractive engineering target (Scott et al., 2000). It is formed from 5,10-methenyl-THF via a side reaction of serine hydroxymethyltransferase. Unlike other folates, 5-formyl-THF is not a donor of one-carbon units (Stover and Schirch, 1993) and its role in plants is unclear, although in seeds at least it may serve as a storage pool
(Shin et al., 1975). One strategy to increase 5-formylTHF content is to block its recycling by suppressing the activity of the enzyme (5-formyl-THF cycloligase) that reconverts it to 5,10-methenyl-THF (Scott et al., 2000). Enhancement of synthesis or accumulation of folate in certain fruits that are high in ascorbate also would be expected to favor its stability.

Another potential strategy for the stabilization of plant folates might be the overexpression of proteins that bind folates. While little is known about the binding state of folates in plants, most folates in mammalian tissues are protein-bound, thus increasing their stability (Matherly and Muench, 1990). It is possible that any gain in folate production achieved by engineering synthesis or transport would be lost if it is not matched by an increase in folate-binding proteins.

\section{Conclusions}

The synthesis pathway of folate in plants is now largely elucidated, and the first trials of metabolic engineering are under way in various laboratories around the world. Since substantial control may reside in the committing steps of the pathway's pterin and $p$ ABA branches, the first engineering attempts have naturally targeted the overexpression of GTPCHI and ADC synthase. Results from these pioneering trials are now becoming available. On the other hand, transport and storage of folates in plants remain open frontiers for further investigations. Research into the transport of folates and their precursors among subcellular compartments is particularly needed. It is also crucial to learn whether folates are transported between plant organs, and if so, whether there are folate source and sink relations between organs. Lastly, any gains made by engineering synthesis or transport might be wiped out if overproduced folates are quickly degraded. It is therefore important to understand how plant folates are catabolized and how they can be stabilized.

\section{REFERENCES}

Anguera, M.C., J.R. Suh, H. Ghandour, I.M. Nasrallah, J. Selhub, and P.J. Stover. 2003. Methenyltetrahydrofolate synthetase regulates folate turnover and accumulation. J. Biol. Chem. 278:29856-29862.

Basset, G.J.C., E.P. Quinlivan, S. Ravanel, F. Rébeillé, B.P. Nichols, K. Shinozaki, M. Seki, L.C. Adams-Phillips, J.J. Giovannoni, J.F. Gregory, and A.D. Hanson. 2004. Folate synthesis in plants: The $p$-aminobenzoate branch is initiated by a bifunctional PabA-PabB protein that is targeted to plastids. Proc. Natl. Acad. Sci. USA.

Basset, G., E.P. Quinlivan, M.J. Ziemak, R. Diaz De La Garza, M. Fischer, S. Schiffmann, A. Bacher, J.F. Gregory, and A.D. Hanson. 2002. Folate synthesis in plants: The first step of the pterin branch is mediated by a unique bimodular GTP cyclohydrolase I. Proc. Natl. Acad. Sci. USA 99:12489-12494.

Bouis, H.E. 2002. Plant breeding: A new tool for fighting micronutrient malnutrition. J. Nutr. 132:491S-494S.

Brown, G.M. 1985. Biosynthesis of pterins. p. 115-154. In R.L. Blakley and S.J. Benkovic (ed.) Folates and Pterins Vol. 2. John Wiley \& Sons, New York.

Cossins, E.A. 2000. The fascinating world of folate and one-carbon metabolism. Can. J. Bot. 78:691-708.

De Saizieu, A., P. Vankan, and A.P. van Loon. 1995. Enzymic characterization of Bacillus subtilis GTP cyclohydrolase I. Evidence for a chemical dephosphorylation of dihydroneopterin triphosphate. Biochem. J. 306:371-377. 
Gambonnet, B., S. Jabrin, S. Ravanel, M. Karan, R. Douce, and F. Rébeillé. 2001. J. Sci. Food Agric. 81:835-841.

Green, J.M., W.K. Merkel, and B.P. Nichols. 1992. Characterization and sequence of Escherichia coli $\mathrm{PabC}$, the gene encoding aminodeoxychorismate lyase, a pyridoxal phosphate-containing enzyme. J. Bacteriol. 174:5317-5323.

Hanson, A.D., and J.F. Gregory. 2002. Synthesis and turnover of folates in plants. Curr. Opin. Plant Biol. 5:244-249.

Hanson, A.D., and S. Roje. 2001. One-carbon metabolism in higher plants. Annu. Rev. Plant Physiol. Plant Mol. Biol. 52:119-137.

Helliwell, C.A., A.N. Chin-Atkins, I.W. Wilson, R. Chapple, E.S. Dennis, and A. Chaudhury. 2001. The Arabidopsis AMP1 gene encodes a putative glutamate carboxypeptidase. Plant Cell 13:2115-2125.

Huangpu, J., J.H. Pak, M.C. Graham, S.A. Rickle, and J.S. Graham. 1996. Purification and molecular analysis of an extracellular $\gamma$-glutamyl hydrolase present in young tissues of the soybean plant. Biochem. Biophys. Res. Commun. 228:1-6.

Kobayashi, K., H.S. Forrest, and M. el-Emary. 1967. Isolation of 6-hydroxymethyllumazine (phosphodoxin?) and two other lumazine derivatives from spinach, and their synthesis. Arch. Biochem. Biophys. 121:220-223.

Kundig, C., A. Haimeur, D. Legare, B. Papadopoulou, and M. Ouellette. 1999. Increased transport of pteridines compensates for mutations in the high affinity folate transporter and contributes to methotrexate resistance in the protozoan parasite Leishmania tarentolae. EMBO J. 18:2342-2351.

Lee, S.W., H.W. Lee, H.J. Chung, Y.A. Kim, Y.J. Kim, Y. Hahn, J.H. Chung, and Y.S. Park. 1999. Identification of the genes encoding enzymes involved in the early biosynthetic pathway of pteridines in Synechocystis sp. PCC 6803. FEMS Microbiol. Lett. 176:169-176.

Lucock, M. 2000. Folic acid: Nutritional biochemistry, molecular biology, and role in disease processes. Mol. Genet. Metab. 71:121-138.

Matherly, L.H., and S.P. Muench. 1990. Evidence for a localized conversion of endogenous tetrahydrofolate cofactors to dihydrofolate as an important element in antifolate action in murine leukemia cells. Biochem. Pharmacol. 39:2005-2014.

Neuburger, M., F. Rébeillé, A. Jourdain, S. Nakamura, and R. Douce. 1996. Mitochondria are a major site for folate and thymidylate synthesis in plants. J. Biol. Chem. 271:9466-9472.

Nichols, B.P., A.M. Seibold, and S.Z. Doktor. 1989. Para-aminobenzoate synthesis from chorismate occurs in two steps. J. Biol. Chem. 264:8597-8601.

Prabhu, V., H. Lui, and J. King. 1997. Arabidopsis dihydropteroate synthase: General properties and inhibition by reaction product and sulfonamides. Phytochemistry 45:23-27.

Prabhu, V., K.B. Chatson, H. Lui, G.D. Abrams, and J. King. 1998. Effects of sulfanilamide and methotrexate on ${ }^{13} \mathrm{C}$ fluxes through the glycine decarboxylase/serine hydroxymethyltransferase enzyme system in Arabidopsis. Plant Physiol. 116:137-144.

Quinlivan, E.P., and J.F. Gregory. 2003. Effect of food fortification on folic acid intake in the United States. Am. J. Clin. Nutr. 77:221-225.

Quinlivan, E.P., J. McPartlin, D.G. Weir, and J.M. Scott. 2000. Mechanism of the antimicrobial drug trimethoprim revisited. FASEB J. 14:2519-2524.

Quinlivan, E.P., S. Roje, G. Basset, Y. Shachar-Hill, J.F. Gregory, and A.D. Hanson. 2003. The folate precursor $p$-aminobenzoate is reversibly converted to its glucose ester in the plant cytosol. J. Biol. Chem. 278:20731-20737.

Ravanel, S., H. Cherest, S. Jabrin, D. Grunwald, Y. Surdin-Kerjan, R. Douce, and F. Rébeillé. 2001. Tetrahydrofolate biosynthesis in plants: Molecular and functional characterization of dihydrofolate synthetase and three isoforms of folylpolyglutamate synthetase in Arabidopsis thaliana. Proc. Natl. Acad. Sci. USA 98:15360-15365.

Rébeillé, F., D. Macherel, J.M. Mouillon, J. Garin, and R. Douce. 1997. Folate biosynthesis in higher plants: Purification and molecular cloning of a bifunctional 6-hydroxymethyl-7,8-dihydropterin pyrophosphokinase/7,8-dihydropteroate synthase localized in mitochondria. EMBO J. 16:947-957.

Roje, S., M.T. Janave, M.J. Ziemak, and A.D. Hanson. 2002. Cloning and characterization of mitochondrial 5-formyltetrahydrofolate cycloligase from higher plants. J. Biol. Chem. 277:42748-42754.

Schoedon, G., U. Redweik, G. Frank, R.G. Cotton, and N. Blau. 1992. Allosteric characteristics of GTP cyclohydrolase I from Escherichia coli. Eur. J. Biochem. 210:561-568.

Scott, J.M. 1984. Catabolism of folates. p. 307-327. In R.L. Blakley and S.J. Benkovic (ed.) Folates and Pterins Vol. 1. John Wiley \& Sons, New York.

Scott, J., F. Rébeillé, and J. Fletcher. 2000. Folic acid and folates: The feasibility for nutritional enhancement in plant foods. J. Sci. Food Agric. 80:795-824.

Shin, Y.S., E.S. Kim, J.E. Watson, and E.L. Stokstad. 1975. Studies of folic acid compounds in nature. IV. Folic acid compounds in soybeans and cow milk. Can. J. Biochem. 53:338-343.

Sirotnak, F.M., and B. Tolner. 1999. Carrier-mediated membrane transport of folates in mammalian cells. Annu. Rev. Nutr. 19:91-122.

Stakhov, L.F., V.G. Ladygin, and L.N. Stakhova. 2002. Effect of ultraviolet $\mathrm{C}$ irradiation on folate and free amino acid contents in leaves of Pisum sativum. Biofizika 47:878-885.

Stover, P., and V. Schirch. 1993. The metabolic role of leucovorin. Trends Biochem. Sci. 18:102-106.

Strålsjö, L.M., C.M. Witthöft, I.M. Sjöholm, and M.I. Jägerstad. 2003. Folate content in strawberries (Fragaria x ananassa): Effects of cultivar, ripeness, year of harvest, storage, and commercial processing. J. Agric. Food Chem. 51:128-133.

Suh, J.R., E.W. Oppenheim, S. Girgis, and P.J. Stover. 2000. Purification and properties of a folate-catabolizing enzyme. J. Biol. Chem. 275:35646-35655.

Suzuki, Y., and G.M. Brown. 1974. The biosynthesis of folic acid. XII. Purification and properties of dihydroneopterin triphosphate pyrophosphohydrolase. J. Biol. Chem. 249:2405-2410.

Sybesma, W., M. Starrenburg, M. Kleerebezem, I. Mierau, W.M. de Vos, and J. Hugenholtz. 2003. Increased production of folate by metabolic engineering of Lactococcus lactis. Appl. Environ. Microbiol. 69:3069-3076.

Titus, S.A., and R.G. Moran. 2000. Retrovirally mediated complementation of the $g l y B$ phenotype. Cloning of a human gene encoding the carrier for entry of folates into mitochondria. J. Biol. Chem. 275:36811-36817.

Yoneyama, T., and K. Hatakeyama. 1998. Decameric GTP cyclohydrolase I forms complexes with two pentameric GTP cyclohydrolase I feedback regulatory proteins in the presence of phenylalanine or of a combination of tetrahydrobiopterin and GTP. J. Biol. Chem. 273:20102-20108. 